\title{
A 75-year-old male with breathlessness and pleuritic chest pain
}

A 75-year-old male was admitted with a 12day history of breathlessness and pleuritic chest pain. He was hypoxic and needed respiratory support in the intensive care unit. A right pleural space collection was identified, which was subsequently drained. The patient had a dental abscess, which had been drained 2 days prior to admission. Subsequently, he developed a right submandibular swelling with erythema.

A computed tomography scan was taken and is shown in figure 1 .

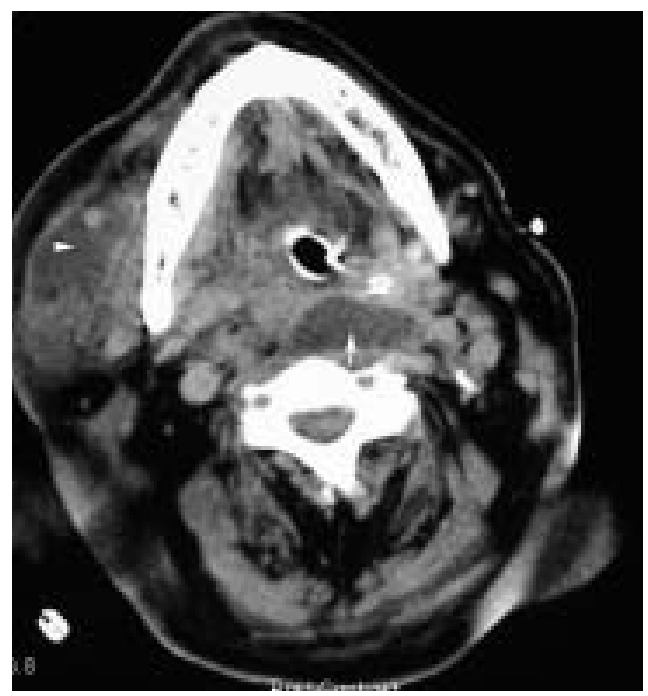

Figure 1

CT scan of the neck.

Task 1

Interpret the CT scan.
The infected tooth was extracted, followed by external drainage of the collection, but the patient remained pyrexial and unwell. He subsequently had further imaging of his chest(figure 2).

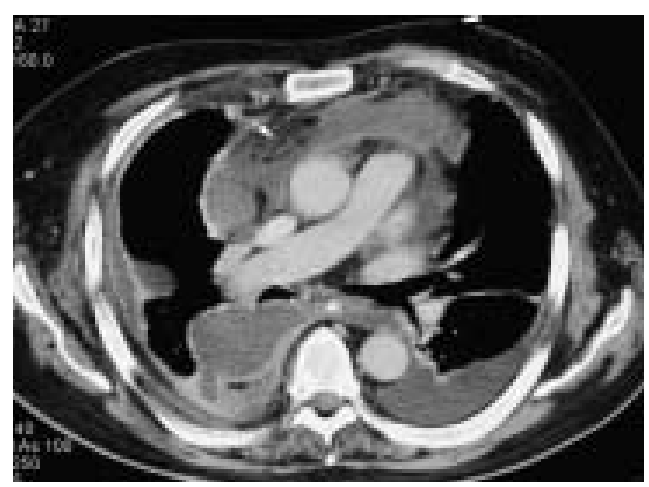

Figure 2

CT scan of the chest.

Task 2

Interpret the CT scan of the chest.

Task 3

Using the information given above, suggest a diagnosis for this patient.

Turn the page for all the answers.

\section{S. Mukherjee}

\section{Correspondence:}

S. Mukheriee

Dept of Respiratory Medicine Queen's Hospital

Belvedere Road

Burton-upon-Trent

DE13 ORB

UK

Fax: 441283593129

E-mail:

smukherjee66@yahoo.com 


\section{Answer 1}

The CT scan of the neck showed a collection of pus in the right submandibular space (arrowhead), along with another collection in the retropharyngeal space (arrow).

\section{Answer 2}

The CT scan of the chest showed bilateral empyema, along with a collection of pus in the mediastinum with gas (arrow).

\section{Answer 3 \\ Descending necrotising mediastinitis.}

\section{Clinical course}

The right-sided empyema was managed conservatively. The left-sided empyema was drained by thoracotomy, while attempting to drain the mediastinal collection. Mediastinal collection was drained under ultrasound control as thoracotomy was not successful. The patient started to improve and was successfully weaned off the ventilator.

\section{Discussion}

Descending necrotising mediastinitis (DNM) is a serious infection, with a high mortality rate $(\sim 40 \%)$ [1]. It is an extension of head and neck infections to the mediastinum, caused by an absence of barriers in the contiguous fascial planes of the neck and mediastinum. In the chest, DNM produces abscesses and empyemas, pleural and pericardial effusions, intrathoracic haemorrhage, and, sometimes, cardiac tamponade [1]. The infection is often polymicrobial and gas producing. DNM is most commonly odontogenic, resulting from a mandibular second or third molar abscess. Other causes include peritonsillar abscess, parotid gland infection and retropharyngeal abscess [2]. Diagnostic criteria for DNM [3] include:

1) clinical evidence of severe oropharyngeal infection

2) characteristic radiological features of mediastinitis

3) documentation of necrotising mediastinal infection

4) establishment of the relationship between the DNM and the oropharyngeal infection.

All of these criteria were met in the patient presented here.

CT scans of the neck and chest are important for early diagnosis, localisation of collections and evaluation of the adequacy of drainage. Combined cervico-thoracic surgical drainage is the gold standard of treatment, along with careful monitoring of airways and administration of broad-spectrum antibiotics [1]. Delays in diagnosis appear to be the most likely reason for the significant mortality [2].

\section{References}

1. Marty-Ane CH, Alauzen M, Alric P, Serres-Cousine 0, Mary H. Descending necrotizing mediastinitis. Advantage of mediastinal drainage with thoracotomy. J Thorac Cardiovasc Surg 1994; 107: 55-61.

2. Haraden BM, Zwemer FL Jr. Descending necrotizing mediastinitis: complication of a simple dental infection. Ann Emerg Med 1997; 29: 683-686.

3. Estrera AS, Landay MJ, Grisham JM, Sinn DP, Platt MR. Descending necrotizing mediastinitis. Surg Gynecol Obstet 1983; 157: 545-552. 